\title{
Blood-brain barrier biology and methodology
}

\author{
William M Pardridge ${ }^{*, 1}$ \\ ${ }^{1}$ Department of Medicine, UCLA School of Medicine, Los Angeles, California, CA 90095-1682, USA
}

\begin{abstract}
The blood-brain barrier (BBB) is formed by epithelial-like high resistance tight junctions within the endothelium of capillaries perfusing the vertebrate brain. Because of the presence of the BBB, circulating molecules gain access to brain cells only via one of two processes: (i) lipid-mediated transport of small molecules through the BBB by free diffusion, or (ii) catalyzed transport. The latter includes carrier-mediated transport processes for low molecular weight nutrients and water soluble vitamins or receptor-mediated transport for circulating peptides (e.g., insulin), plasma proteins (e.g., transferrin), or viruses. While BBB permeability, per se, is controlled by the biochemical properties of the plasma membranes of the capillary endothelial cells, overall brain microvascular biology is a function of the paracrine interactions between the capillary endothelium and the other two major cells comprising the microcirculation of brain, i.e., the capillary pericyte, which shares the basement membrane with the endothelial cell, and the astrocyte foot process, which invests $99 \%$ of the abluminal surface of the capillary basement membrane in brain. Microvascular functions frequently ascribed to the capillary endothelium are actually executed by either the capillary pericyte or the capillary astrocyte foot process. With respect to BBB methodology, there are a variety of in vivo methods for studying biological transport across this important membrane. The classical physiologic techniques may now be correlated with modern biochemical and molecular biological approaches using freshly isolated animal or human brain capillaries. Isolated brain capillary endothelial cells can also be grown in tissue culture to form an 'in vitro BBB' model. However, BBB research cannot be performed using only the in vitro $\mathrm{BBB}$ model, but rather it is necessary to correlate observations made with the in vitro BBB model with in vivo studies.
\end{abstract}

Keywords: endothelium; cell culture; pericyte; astrocyte; biological transport

\section{Introduction}

Blood-brain barrier (BBB) permeability is regulated by brain capillary endothelial transport properties. Microvascular biology in the central nervous system (CNS) is regulated by paracrine interactions between the capillary endothelium in brain and its neighboring cells: the pericyte (which shares the capillary basement membrane with the endothelium), the astrocyte foot process (which invests 99\% of the abluminal surface of the brain capillary), the smooth muscle cell (which invests the endothelium of pre-capillary arterioles), and neuronal endings (which directly innervate either the capillary endothelium or the astrocyte foot process investing

${ }^{*}$ Correspondence: WM Pardridge

Received 12 February 1999; revised 21 April 1999; accepted 26 April 1999 the capillary endothelium) (Cohen et al, 1995; Paspalas and Papadopoulos, 1996).

In this overview of BBB methodology and biology, two general theses are discussed. First, with respect to $\mathrm{BBB}$ methodology, it is presently not possible to accurately investigate BBB transport processes using 'in vitro BBB models' without in vivo correlation. In the in vitro models, brain capillary endothelial cells are grown in tissue culture and transport across the endothelial monolayer is investigated, with or without astrocyte cocultures (Dehouck et al, 1990). The in vitro BBB model can be a useful adjunct when performed in conjunction with in vivo investigations of the BBB. However, when in vitro BBB models are used in isolation, the limitations of this model reviewed below become a limiting factor in interpretation of the data. Second, with regard to BBB biology, the 
brain microvasculature is comprised of at least three cells (endothelia, pericytes, and astrocyte foot processes), and important brain microvascular functions are performed by either the pericyte or the astrocyte foot process. However, these functions are frequently assigned to the endothelial cell, because the role played by either the pericyte or the astrocyte foot process is ignored. While the endothelial cell regulates BBB permeability, per se, overall brain microvascular function is regulated by the paracrine interactions between the endothelial cell, the pericyte, and the astrocyte foot process, as well as direct neuronal innervation of the microvasculature.

\section{Blood-brain barrier methodology}

Until the late 1960's, blood-brain barrier function in vivo was studied with vital dyes such as trypan blue. These large molecular weight, highly anionic dyes that are tightly bound by albumin, do not cross the BBB in vivo with two exceptions. First, there are a half dozen tiny areas of the brain, called circumventricular organs (CVOs), such as the choroid plexus, that are perfused by porous fenestrated capillaries. Second, in pathophysiologic conditions, there may be BBB disruption, leading to focal uptake of vital dyes. Subsequently, animals were administered horseradish peroxidase (HRP) followed by peroxidase histochemistry of brain tissue sections, and visualization of brain at either the light microscopic or electron microscopic level (Figure 1). Around 1970, radioisotopes were introduced and these, in conjunction with physiologic techniques, or brain imaging methods (Figure 1), allowed for the quantitative assessment of BBB permeability in vivo. In the 1970s, techniques for isolation of brain microvessels were introduced and this allowed for subsequent isolation of BBB plasma membranes for biochemical assays and radioreceptor studies (Pardridge, 1998b). However, brain capillaries, isolated with either a mechanical homogenization technique or an enzymatic homogenization method, are not metabolically viable and have very low levels of ATP (Lasbennes and Gayet, 1983). The low ATP concentration in brain capillaries freshly isolated with an enzymatic homogenization technique is somewhat of an enigma since it is possible to isolate other cells of the body with enzymatic homogenization techniques and these cells have normal levels of ATP. Isolated brain capillaries provide an intact membrane preparation of the BBB and the brain microvasculature, and allow for experiments that cannot be done with other methodologies. In the 1980s, brain capillary endothelial cells were plated in tissue culture and this led to the early in vitro

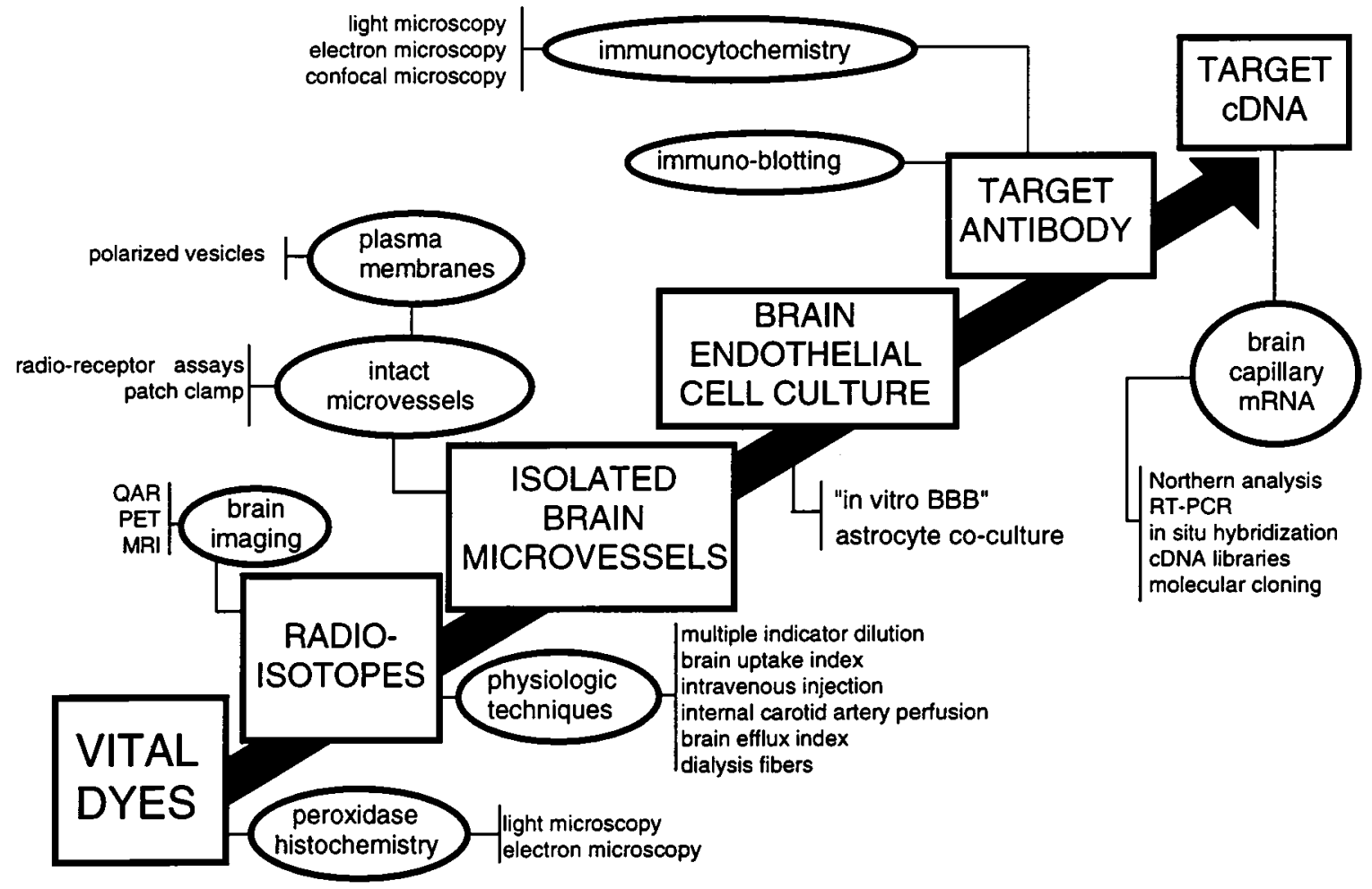

Figure 1 Linear evolution of blood-brain barrier methodology from vital dyes to molecular biology. From Pardridge (1998a). 
BBB models (De Bault et al, 1979; Bowman et al, 1983). However, it became apparent that brain capillary endothelial cells grown in tissue culture lack many of the properties of the BBB in vivo and this gave rise to endothelial/astrocyte co-cultures. Initially, it was thought that soluble factors secreted by cultured astrocytes could be added to endothelial cultures to induce BBB properties, but in the last 20 years, this approach has not led to any significant progress in the molecular identification of the putative factors. This lack of progress has given rise to the hyopthesis that in order to observe induction of BBB properties in endothelial cells grown in culture, it is necessary for there to be physical contact between astrocytes and endothelial cells in culture (Meyer et al, 1991). The physical contact can arise from either the use of mixed cultures, where endothelial cells and astrocytes are both plated on the same dish in culture, or in a coculture system where endothelial cells and astrocytes are plated on opposite sides of a porous filter and the diameter of the pores are sufficiently large to allow for protrusion of astrocyte processes through the pores so that there can be cell-cell contact between the astrocyte foot process and the endothelium. These endothelial-astrocyte contacts in tissue culture culture are only focal contacts and do not approximate the complete investment of the endothelial cell by astrocyte foot processes that takes place in vivo. In the 1990s, the production of target specific antibodies and target specific cDNAs has allowed for biochemical and molecular biological investigations of blood-brain barrier transport processes (Figure 1). A particularly valuable approach is to use specific antibodies or cDNAs to investigate the expression of proteins or mRNAs in freshly isolated brain microvessels. As reviewed in subsequent sections of this chapter, the immunocytochemistry of cytocentrifuged brain capillaries allows for differentiation between endothelial cells, pericytes, and astrocyte foot processes in a way that cannot be readily done with immunohistochemistry of brain tissue sections. The isolation of poly(A)+ mRNA from freshly isolated brain capillaries allows for direct molecular biological investigations of the cells comprising the BBB in vivo. Since the brain capillary endothelial cell volume is only $1 \mu \mathrm{L} / \mathrm{g}$ brain, the endothelial volume in brain is only $0.2 \%$ of the total cell volume in brain. Therefore, it is generally not possible to perform BBB molecular biological studies from poly(A) ${ }^{+}$mRNA isolated from whole brain extracts. Rather, it is necessary to first isolate brain capillaries and then isolate the capillary derived poly (A) ${ }^{+}$mRNA for BBB molecular biological studies (Boado and Pardridge, 1991).

Despite the array of methodologies available for performing $\mathrm{BBB}$ investigations (Figure 1), there has been a long tradition within BBB research to study this important biological membrane with a single methodology. One lab may exclusively use an internal carotid artery perfusion method, whereas another lab may exclusively use an intravenous injection technique, or another lab may exclusively use quantitative autoradiography (QAR). The latest variation in this trend is to study $\mathrm{BBB}$ transport processes exclusively with the in vitro BBB cell culture model. Brain capillary endothelial cells can be grown as a monolayer in tissue culture (Figure 2B) and these cells are grown on filters with specified porosity and then placed in side-by-side transport chambers for studies of transport across the monolayer (Figure 2A), in a way that was originally performed with drug studies of skin transport (Audus et al, 1990). A given radiolabeled drug may be placed on one side of the transport chamber and movement across the endothelial monolayer may be investigated by sampling the 'acceptor chamber.' From these clearance studies performed with filter plus endothelial monolayer as well as filter alone, the endothelial monolayer permeability-surface area (PS) product may be computed (Pardridge et al, 1990). The PS product for a series of drugs, as well as D-glucose or L-DOPA, with normalization for molecular weight $\left(\mathrm{M}_{\mathrm{r}}\right)$, are plotted versus the 1-octanol lipid partition coefficient (PC) as shown in Figure 2B. This linear correlation between PS products across the endothelial monolayer and the lipid solubility could be taken as evidence for the reliability of the in vitro BBB model for assessing drug transport. However, quantitative analysis of this data reveals the following two caveats. First, the slope of the plot of the in vitro PS product and the lipid PC is approximately 150-fold smaller than the slope generated by measuring the BBB PS product with an in vivo technique, the internal carotid artery perfusion technique (Pardridge et al, 1990). That is, the in vitro $\mathrm{BBB}$ is $>150$-fold leakier than the in vivo BBB. Accordingly, the transport of drugs across the BBB that occurs via lipid mediated transport is over-estimated by more than a 100 -fold by the in vitro BBB model (Figure 2B). Similarly, the electrical resistance across the endothelial monolayer grown in the absence of astrocytes is approximately $80 \Omega . \mathrm{cm}^{2}$. This is approximately 100 -fold less than the electrical resistance across the $\mathrm{BBB}$ in vivo which is estimated to be $8000 \Omega . \mathrm{cm}^{2}$ (Smith and Rapoport, 1986). Although the electrical resistance across pial vessels on the surface of the brain is of the order of $1000-2000 \Omega . \mathrm{cm}^{2}$, these vessels do not have a complete BBB, as the vessels are invested only by a glial limitans. The electrical resistance across pial vessels is more than fourfold lower than the electrical resistance across parenchymal vessels with an intact BBB. The electrical resistance across an endothelial monolayer in tissue culture is as high as $400-1000 \Omega . \mathrm{cm}^{2}$ using special substrata such as type 4 collagen and fibronectin (Tilling et al, 1998), but these values are still a log order lower than the electrical resistance across the BBB in vivo. 
A

\section{BOVINE BRAIN CAPILLARY ENDOTHELIUM IN TISSUE CULTURE (BCEC)}
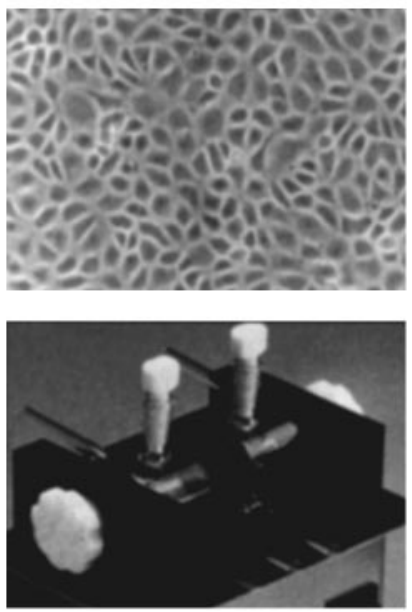

SIDE-BY-SIDE TRANSPORT CHAMBERS

B

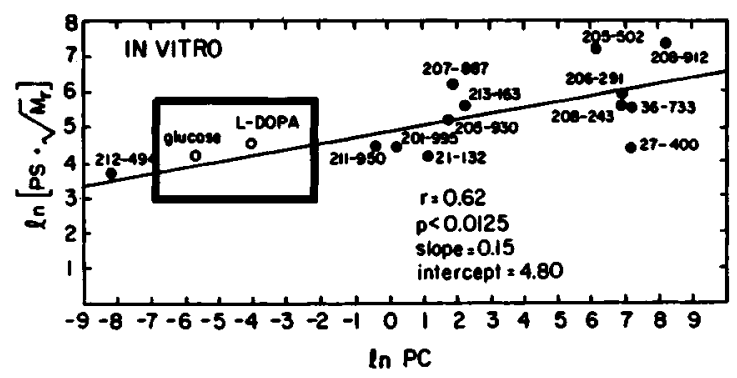

PLOT IN VITRO PERMEABILITY-SURFACE AREA (PS) PRODUCT VS LIPID PARTITION COEFFICIENT (PC)

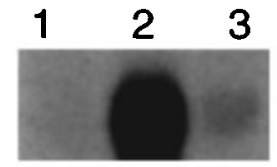

lane 1: BCEC

lane 2: isolated bovine brain capillaries

lane 3: total bovine brain

Glut1 glucose

transporter

NORTHERN BLOT

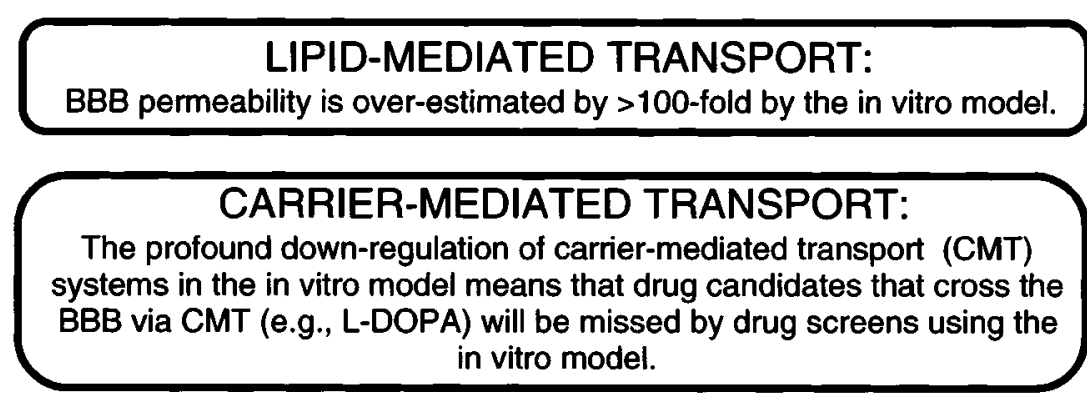

Figure 2 (A) Bovine brain capillary endothelium in tissue culture (BCEC) is shown in the top panel. The endothelial cells are grown on filters which are then placed in side-by-side transport chambers (bottom panel) to establish an 'in vitro BBB model.' (B) The permeability-surface area (PS) product for glucose, L-DOPA, and radiolabeled drugs is plotted versus the 1-octanol lipid partition coefficient (PC). The PS products were measured with the in vitro BBB model system and normalized for molecular weight ( $\left.\mathrm{M}_{\mathrm{r}}\right)$. The correlation line was drawn by eye, whereas the slope and intercept were determined by linear regression analysis. A Northern blot showing profound down-regulation of the GLUT1 glucose transporter mRNA in the BCEC is shown in lane 1. The GLUT1 glucose transporter Northern blot signal for freshly isolated bovine brain capillaries or total bovine brain is shown in lanes 2 and 3 . From Pardridge et al (1990) and Boado and Pardridge (1990).

The second observation noted in the plot of the in vitro PS product versus the lipid PC is that the values for D-glucose and L-DOPA, two molecules that undergo carrier-mediated transport through the $\mathrm{BBB}$ in vivo via the hexose carrier and the large neutral amino acid carrier, respectively, fall on the lipid solubility trend line (Figure 2B). Conversely, when the PS product for these two molecules is measured with an in vivo technique, the internal carotid perfusion method, the PS product for these two molecules is 4-5 log orders above the lipid solubility trend line (Pardridge et al, 1990). In other words, there is a profound down-regulation of the activity of the glucose or neutral amino acid carrier in the in vitro BBB model. This down-regulation can also be seen with molecular biological techniques wherein the mRNA for the GLUT1 glucose transporter in capillary endothelial cells in tissue culture and in freshly isolated bovine brain capillaries is measured in parallel (Boado and Pardridge, 1990). The Northern blot in Figure 2B shows the signal representing the GLUT1 glucose transporter mRNA in isolated brain capillaries is more than 100-fold greater than the transcript in endothelial cells grown in tissue culture (lane 1, Figure 2B) or in total brain (lane 3, Figure 2B). The greater density of the GLUT1 glucose transporter in isolated brain capillaries as compared to total brain reflects the fact that this transcript is expressed in normal brain principally at the endothelium in brain and not in neurons or astrocytes in vivo. The down-regulation of carrier-mediated transport (CMT) systems in the in vitro $\mathrm{BBB}$ model means that drug candidates that cross the BBB via CMT (e.g. L-DOPA) will be missed by drug screens using in vitro $\mathrm{BBB}$ models. In addition to carrier mediated transport systems, there is also a marked down-regulation of enzymes in the in vitro BBB model, that normally comprise the 'enzymatic BBB' in vivo (van Bree et al, 1988; Thompson and Audus, 1994).

In an attempt to make the in vitro BBB model more accurately reflect the BBB in vivo, there have been several innovations in the in vitro BBB model. One innovation is to use a homologous co-culture system (Hurwitz et al, 1993), whereby human fetal brain primary astrocytes are grown with human umbilical vein endothelial cells in primary culture in a co-culture format using a three micron pore. It 
Blood-brain barrier WM Pardridge

was found that the GLUT1 glucose transporter in the endothelial cell could be induced by astrocytes if the filter contained a three micron pore that allowed for the astrocyte foot processes to pass through and come in contact with the endothelial cells. When the co-cultures were grown on filters with 0.45 micron pores, there was no induction of the GLUT1 glucose transporter because this pore diameter was too small to allow for passage of the astrocyte foot process (Hurwitz et al, 1993). More recently, hollow fiber tubes with diameters $>50$ microns, and pore sizes of 0.5 microns have been used to establish endothelial astrocyte co-cultures (Stanness et al, 1997). Given the small size of the pore diameter (0.5 microns), there may be minimal cell-cell contact between the astrocytes grown on the exterior side of the cylinder with the endothelial cells grown on the interior side. This model has unusual properties that are not found at the BBB in vivo. For example, the endothelial permeability coefficient $(\mathrm{Pe})$ for Laspartic acid, an acidic amino acid that normally does not cross the BBB in vivo, is higher than the $\mathrm{BBB}$ Pe value for the theophylline, a lipid soluble small molecule that is freely transported across the BBB in vivo (Stanness et al, 1997). In this model, the permeability coefficient for sucrose is quite low, approximately $20 \times 10^{-8} \mathrm{~cm} / \mathrm{s}$ after a $10 \mathrm{~min}$ perfusion, but increases 25 -fold to $500 \times 10^{-8} \mathrm{~cm} / \mathrm{s}$ after a 60 min perfusion. This increase in Pe in the in vitro model suggests the in vitro $\mathrm{BBB}$ becomes leaky with a 60 min perfusion.

In summary, after 20 years, there are still major limitations in establishing an in vitro BBB model. This model is a useful adjunct in investigating BBB transport processes when used in conjunction with one of the many in vivo methodologies available (Figure 1). However, when the in vitro model is used alone, it is difficult to extrapolate the data obtained with this model to the BBB permeability properties in vivo. In many cases, data obtained with in vitro BBB culture models replicate more the properties of fibroblasts in culture rather than the BBB in vivo.

\section{Blood-brain barrier biology}

Three cell model of the brain microvasculature The three cell model of the brain microvasculature is depicted in Figure 3, wherein the central endothelial cell, which regulates BBB permeability, shares intimate relationships with two other cells, the pericyte and the astrocyte foot process. The pericyte is a phagocytic cell that shares a common basement membrane with the capillary endothelial cell (Cancilla et al, 1972). In isolated brain capillary preparations, there is approximately one pericyte for every three endothelial cells. An enzyme, $\gamma$ glutamyl transpeptidase, that is frequently used as a 'brain endothelial marker,' is also localized to pericytes in the brain microvasculature (Risau et al, 1992).

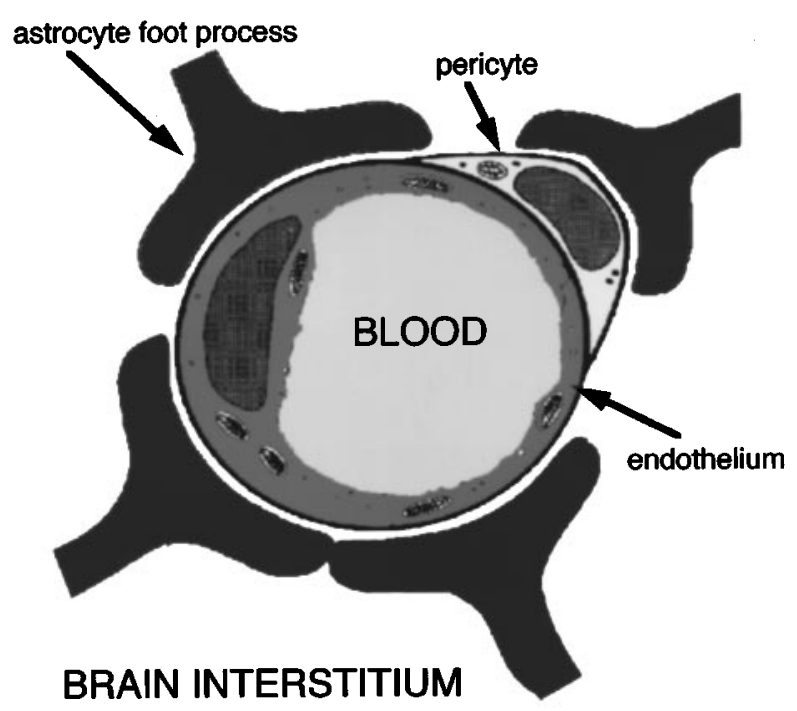

Figure 3 The three cell model of the brain microvasculature emphasizes the paracrine interactions between the brain capillary endothelium, the pericyte, and the astrocyte foot process. From Pardridge (1999).

The astrocyte foot process invests $99 \%$ of the brain surface of the capillary basement membrane. The intimate relationship between the astrocyte foot process and the endothelial cell in brain was illuminated by recent confocal microscopy studies performed by Kacem et al (1998). Antibodies to either an endothelial marker, the GLUT1 glucose transporter, or to an astrocyte foot process marker, glial fibrillary acidic protein (GFAP), were used in immunofluorescent confocal microscopy of brain sections with threedimensional reconstruction of serial confocal sections. The endothelial GLUT1 glucose transporter is seen in yellow in panel 1 of Figure 4 and the astrocyte foot process marker, GFAP, is seen as red in panel 1 of Figure 4 . There is a clear demarcation between the cellular localization of GLUT1 glucose transporter immunoreactivity and astrocyte GFAP immunoreactivity, indicating the GLUT1 glucose transporter is expressed exclusively within the endothelial cell and the GFAP is produced exclusively within the astrocyte foot process. The extensive investment of a microvessel by astrocyte foot processes is shown in panel 2 of Figure 4 and the outline of a microvessel can be clearly delineated using an antibody to an astrocyte foot process marker such as GFAP. Indeed, when performing immunocytochemistry of brain tissue sections with GFAP antibodies, those antibodies can frequently give an immunocytochemical picture comparable to that obtained with an antibody to an endothelial antigen (Stewart, 1994). The analysis by Kacem et al (1998) shows astrocyte foot processes forming 

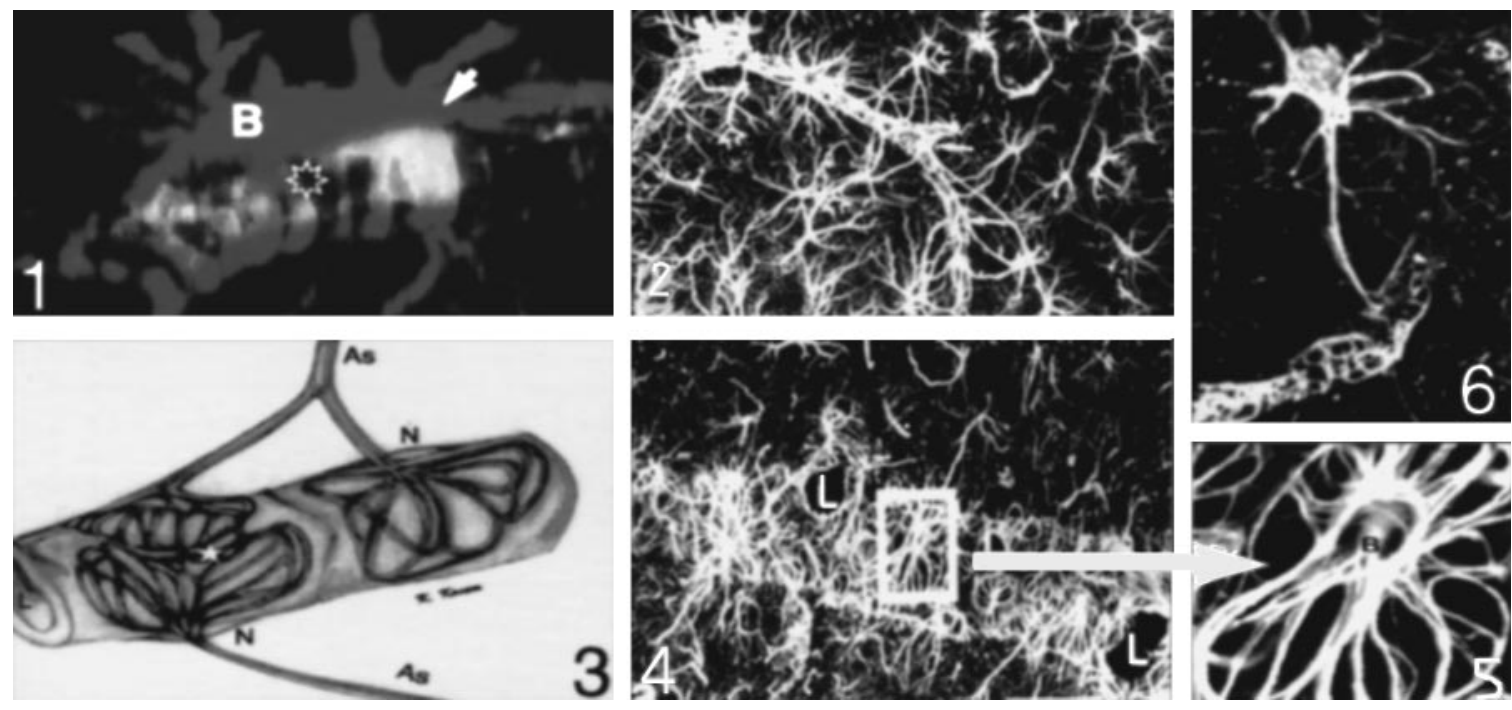

Figure 4 Immunofluorescent confocal microscopy shows the three-dimensional relationship between brain capillary endothelium and astrocyte foot processes. In panel 1, the endothelial GLUT1 glucose transporter is shown in yellow, and the astrocyte foot process marker, glial fibrillary acidic protein (GFAP) is shown in red. The monoclonal antibody to GFAP allows for illumination of the microvascular astrocyte foot processes as shown in panels 2 and 4. Astrocyte foot processes form rosette-like structures at the albuminal surface of the endothelium as schematized in panel 3 and shown in high magnification in panel 5. Panels 1-5 are from Kacem et al (1998) and panel 6 is from Blumcke et al (1995).

rosette-like structures at the albuminal surface of the endothelium (panel 3, Figure 4). Astrocytes were found to send processes to only single endothelial cells, although one endothelial cell may receive inputs from multiple astrocytes (Kacem et al, 1998). The rosette-like structure formed by astrocyte foot processes surrounding the capillary endothelium is seen at low magnification in panel 4 of Figure 4 and at high magnification in panel 5 of Figure 4. A complete astrocyte/endothelial interaction is shown in panel 6 of Figure 4, wherein a single astrocyte foot process is seen to invest a single endothelial cell.

The distance between an astrocyte foot process and a capillary endothelium is only 200 Angstroms in vivo or 20 nanometers (Paulson and Newman, 1987). This space is filled by the thickness of the capillary basement membrane. Astrocytes signal neurons in tissue culture (Nedergaard, 1994), and signal endothelial cells in culture and most likely send signals to these cells in vivo. It has yet to be shown that brain endothelial cells send signals to astrocytes or even neurons in vivo. With respect to the myocardium, it is known that myocardial autoregulation is modulated by cyclic AMP regulation of myocardial contractility via endothelialderived fctors (McClellan et al, 1993). Myocardial contractile function is in part regulated by the myocardial endothelial cell. The extent to which neuronal transmission and brain function is regulated by signals emanating from capillary endothelial cells in brain is at present unknown.
P-glycoprotein in astrocyte foot processes

P-glycoprotein is an active efflux system that is responsible for pumping drugs out of cells. Immunoreactive p-glycoprotein was found in the microvasculature in tissue sections of brain (Cordon-Cardo et al, 1989) and in isolated brain capillaries (Jette et al, 1993). On the basis of these studies, it was assumed that immunoreactive pglycoprotein at the brain microvasculature was endothelial in origin and regulated drug transport across the BBB in vivo. While this mechanism may operate in rodents, recent studies with isolated human brain microvessels indicate human brain microvascular p-glycoprotein immunoreactivity is essentially entirely confined to the astrocyte foot process with minimal, if any, expression in the capillary endothelium (Figure 5). In these studies, an antibody was used to the GLUT1 glucose transporter endothelial marker, an antibody was used to the GFAP astrocyte foot process marker, and the MRK16 murine monoclonal antibody to human p-glycoprotein was used to identify this drug transport system (Pardridge et al, 1997). Confocal microscopy of cytocentrifuged isolated human brain capillaries was performed to allow for colocalization of either the GLUT1 glucose transporter and GFAP or p-glycoprotein and GFAP. Confocal immunofluorescence microscope images of dual labeled unfixed human brain capillaries is shown in Figure 5 (Golden and Pardridge, 1999). The discontinuous staining pattern of MRK16 is demonstrated by the single channel scan for texas red (A), while a single channel scan for fluorescein (B) 

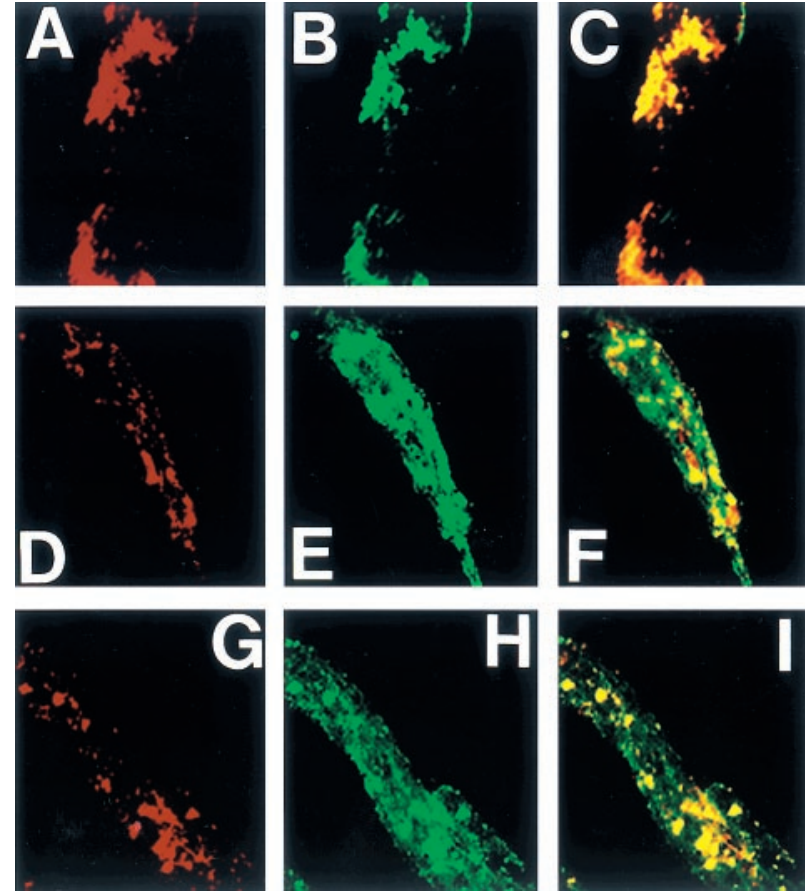

Figure 5 Confocal fluorescent microscopic images of dual labeled isolated human brain capillaries cytocentrifuged to a glass slide and stained with antisera to the GLUT1 glucose transporter (an endothelial marker), to GFAP (an astrocyte foot process marker), or p-glycoprotein. (A) P-glycoprotein immunoreactivity, (B) GFAP immunoreactivity, (C) Co-localization of pglycoprotein and GFAP, (D) P-glycoprotein immunoreactivity, (E) GLUT1 glucose transporter immunoreactivity, (F) Colocalization of p-glycoprotein and GLUT1 glucose transporter, (G) GFAP immunoreactivity, (H) GLUT1 glucose transporter immunoreactivity, (I) GFAP and GLUT1 glucose transporter immunoreactivity overlap. Images $(\mathbf{A}-\mathbf{C})$ : 20 micron $\times 20$ micron; images $(\mathbf{D}-\mathbf{I})$ : 40 micron $\times 40$ micron. From Golden and Pardridge (1999).

demonstrates the identical discontinuous staining pattern of anti-GFAP labeling of astrocyte foot processes. Dual channel scanning of the field (C) demonstrates complete co-localization of MRK16, indicated by the yellow signal, where the red and green signals overlap. In contrast, discontinuous labeling of immunoreactive p-glycoprotein by MRK16 (D) is not co-localized with the continuous labeling provided by an anti-GLUT1 glucose transporter antiserum (E). The dual channel scan (F) demonstrates preservation of the texas red signal for MRK16 in a discontinuous pattern. Similar results were obtained with capillaries dual-labeled with antibodies against GFAP (G) and GLUT1 glucose transporter $(\mathrm{H})$. The similarity of the overlapping image provided by dual-channel screening for GFAP and GLUT1 localization (I) to that observed for p-glycoprotein and GLUT1 glucose transporter (F) indicates that the discontinuous localization patterns for GFAP and p-glycoprotein on the astrocyte foot processes differ from that of the continuous staining of the endothelial glucose transporter. Results of this study indicate that the immunoreactive p-glycoprotein is localized to the astrocyte foot processes of the albuminal surface of the human brain microvasculature. The localization of p-glycoprotein drug efflux at the astrocyte plasma membrane may alter the distribution of drugs behind the BBB without directly affecting brain endothelial permeability to drugs. P-glycoprotein is an example of a brain microvascular antigen that is localized to the astrocyte foot process rather than the endothelium.

\section{Does the capillary pericyte in brain have a contractile function?}

Capillary pericytes in brain are said to have a contractile function and to be the smooth muscle analog of the capillary. Contractile cells such as smooth muscle cells express the $\alpha$-actin isoform. The $\alpha$-actin gene is expressed in brain capillary pericytes grown in tissue culture (Herman and D'Amore, 1985). However, immunoreactive $\alpha$-actin is not expressed in pericytes in vivo in microvessels of bovine retina (Nehls and Drenckhahn, 1991). Similarly, the pericytes in vivo of brain capillaries do not express immunoreactive $\alpha$-actin, as demonstrated by the immunocytochemical studies using cytocentrifuged isolated bovine brain capillaries and a monoclonal antibody to $\alpha$-actin (Figure 6). As shown in (A), smooth muscle cells of pre-capillary arterioles in isolated bovine brain microvessels are highly immunoreactive for $\alpha$-actin. Higher magnification (B and C) shows immunoreactive $\alpha$-actin (Boado and Pardridge, 1994) is localized only to smooth muscle cells of pre-capillary arterioles and is not found at the capillary level in either endothelial cells or pericytes. The pericyte nuclei are distinguishable from endothelial nuclei, which have a more ovoid shape, and the pericyte nuclei are indicated in B and C by arrows. The absence of immunoreactive $\alpha$-actin in pericytes of either brain or retina microvessels in vivo suggests brain capillary pericytes do not have a contractile function in vivo under normal conditions. In pathophysiologic state such as high flow/shear states (Liwnicz et al, 1990), it is possible that $\alpha$ actin is expressed in capillary pericytes, but this has yet to be demonstrated in vivo. The absence of $\alpha$ actin expression in capillary pericytes in vivo, and the abundant expression of $\alpha$-actin in capillary pericytes grown in tissue culture, again emphasizes the need for in vitro/in vivo correlations when examining brain microvascular cells in tissue culture alone.

Antigen presentation at the brain microvasculature in vivo: role of the capillary pericyte

The CNS is said to be an immune priviliged site, because of the minimal antigen presentation that is assumed to occur in brain (Pollack and Lund, 1990). 

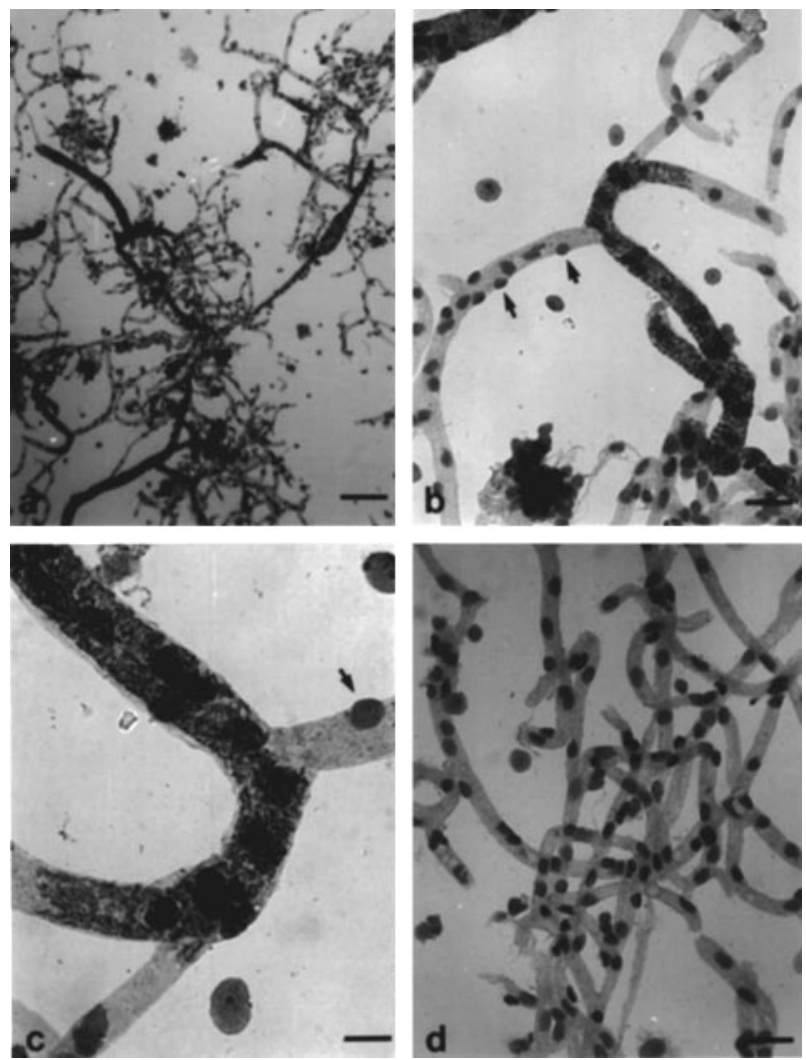

Figure 6 Light microscopic immunocytochemistry of cytocentrifuged bovine brain capillariers immunostained with either a mouse monoclonal antibody to the $\alpha$-actin isoform (A, $\mathbf{B}$ and $\mathbf{C}$ ) or a mouse IgG $_{2 \mathrm{a}}$ isotype control (D). There is specific staining of the $\alpha$-actin isoform in the smooth muscle cells of pre-capillary arterioles, but there is no immunoreactive $\alpha$-actin detected in capillary pericytes as indicated by the arrows in (B and $\mathbf{C}$ ). Magnification bar equals 93 micron (A), 23 microns (B and D), and 9 microns (C). From Boado and Pardridge (1994).

Class II histocompatibility antigens, such as the DRantigen, are very low in brain (Wong et al, 1984). However, if DR-antigen immunoreactivity is localized primarily to the microvasculature in brain and not to brain cells, then overall brain DR-immunoreactivity will be low, owing to the small volume of brain represented by microvascular cells. The presence of the DR-antigen in human brain microvessels was examined with cytocentrifuged human brain capillaries using a monoclonal antibody to the human DR-antigen (Pardridge et al, 1989). As shown in A of Figure 8, there is abundant DRantigen immunoreactivity in the pre-capillary arteriolar smooth muscle cells of microvessels isolated from brains of subjects dying without neurologic disease. Conversely, when microvessels were isolated from Multiple Sclerosis (MS) plaque tissue, there was abundant DR-antigen immunoreactivity at the capillary level, but this was not found in endothelial cells, but was found in capillary pericytes, as shown at low magnification in B and at high magnification in panel C (Figure 7). The expression of the DR-antigen in capillary pericytes, and not in capillary endothelial cells, means that antigen presentation in brain occurs beyond the BBB as shown in D of Figure 7 . Activated lymphocytes may undergo diapedesis through the capillary endothelial barrier (Vass et $a l, 1986)$, and present antigen to either capillary pericytes or arteriolar smooth muscle cells. The expression of the DR-antigen in capillary pericytes may be under the regulation of cytokines as the incubation of isolated rat brain capillaries with interferon $\gamma$ for $18 \mathrm{~h}$ results in an increase in pericyte DR-antigen immunoreactivity (Dore-Duffy et al, 1994).

\section{Multiple sclerosis and the blood-brain barrier}

The earliest lesion of MS is around brain blood vessels and this observation was noted in the early 1900's (Broman, 1964; Daniel et al, 1981). Similarly, the earliest lesion is microvascular in experimental allergic encephalomyelitis (EAE) and in postvaccinal disease or post-infectious encephalomyelitis. The search for autoantibodies to the endothelial cells in MS has been generally negative although these searches have employed human umbilical endothelial cells, instead of capillaries isolated from MS plaque tissue (Tsukada et al, 1985). When guinea pigs are immunized with rat brain capillary membranes, EAE develops and the earliest lesion is macrophages infiltrating post capillary venules and demyelination, even though the animals were not initially immunized with myelin antigens (Tsukada et al, 1987). Considering the earliest legion of MS is microvascular and considering the ease with which microvessels may be isolated from MS human autopsy brain plaque tissue (Pardridge et al, 1987; Washington et al, 1994), it is somewhat surprising that there are so few studies on the immunology and biochemistry of capillaries isolated from MS plaque tissue.

Endothelial receptor-mediated transcytosis systems Carrier mediated transport (CMT) systems exist for a small molecule nutrients such as glucose, amino acids, monocarboxylic acids, purine bases, choline, thyroid hormones, and several water soluble vitamins. CMT processes use stereospecific transporters localized within the endothelial luminal and albuminal membranes that operate within milliseconds. In addition, certain circulating peptides such as insulin, transferrin, leptin, and insulin-like growth factors (IGF) undergo transport through the capillary endothelium via receptor mediated transcytosis (RMT) processes which occur within minutes. RMT is comprised of three steps: receptor mediated endocytosis of the circulating peptide at the luminal side of the capillary endothelium, movement through the $200 \mathrm{~nm}$ of 


ân
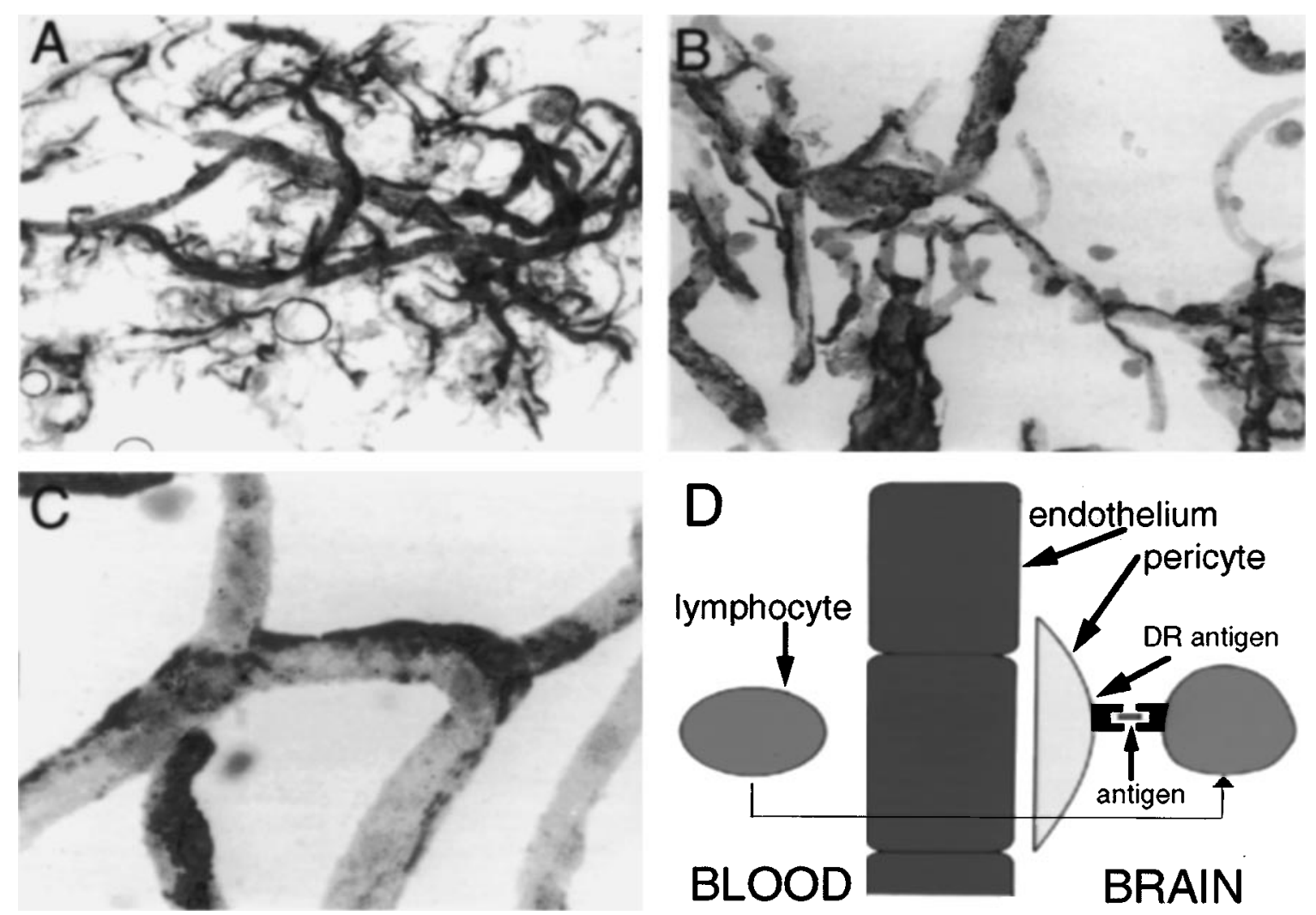

Figure 7 Light microscopic immunocytochemistry of cytocentrifuged human brain capillaries stained with a mouse monoclonal antibody to the human DR-antigen. Microvessels were isolated from either control human brain (A) or multiple sclerosis plaque (B and C). Magnification: $25 \times$ (A), $100 \times$ (B), $250 \times$ (C). (D) Model for antigen presentation in brain. From Pardridge et al (1989).

endothelial cytoplasm, and exocytosis of the peptide into the brain interstitial space (Pardridge, 1991). Circulating transferring undergoes RMT through the $\mathrm{BBB}$ via the capillary endothelial transferrin receptor. The ultrastructural basis of the transferrin RMT process was investigated with a $5 \mathrm{~nm}$ gold conjugate of the OX26 murine monoclonal antibody to the rat transferrin receptor (Bickel et al, 1994). The gold-OX26 conjugate was infused into the internal carotid artery of anesthetized rats for 10 min followed by saline perfusion of the brain microvasculature to clear residual conjugate from the luminal compartment, followed by in situ perfusion fixation with $2 \%$ glutaraldehyde, embedding, and visualization at the light microscopic level with immunogold silver staining (A, Figure 8). At the electron microscopic level, the gold-OX26 conjugate was visible within the endothelial cell in 100 nanometer endosomal structures as shown at low magnification in B and high magnification in D of Figure 8. The exocytosis of the conjugate into the brain interstitial fluid is shown at high magnification in $\mathrm{C}$ of Figure 8 and the overall scheme for RMT of transferrin (Tf) via the BBB transferrin receptor (TfR) is depicted in D of Figure
8. The RMT of transferrin through the BBB is a model of not only new pathways for drug delivery to the brain, but also a model for how viruses may enter the brain from the circulation.

\section{Drug delivery to the brain via blood-brain barrier receptor-mediated transport systems}

Similar to the transferrin receptor, there is an insulin receptor at the $\mathrm{BBB}$ and this mediates the RMT of insulin through the endothelial barrier in vivo. $\left.{ }^{[25} \mathrm{I}\right]$ insulin was infused into the carotid artery of 1-month old rabbits for $10 \mathrm{~min}$ and the animals were then sacrificed by decapitation and the brain was rapidly frozen for thaw-mount autoradiography (Duffy and Pardridge, 1987). A dark field micrograph of the brain microvasculature is shown in A of Figure 9 and indicates that insulin is trapped in the capillary lumen. However, radioactive insulin is also found well within the brain parenchyma following a 10 min carotid artery perfusion. Reverse phase HPLC of acid ethanol extracts of brain showed that the radioactivity within brain parenchyma was unmetabolized insulin rather than an insulin degradation product. The transport of insulin into brain parenchyma was saturable (Duffy 

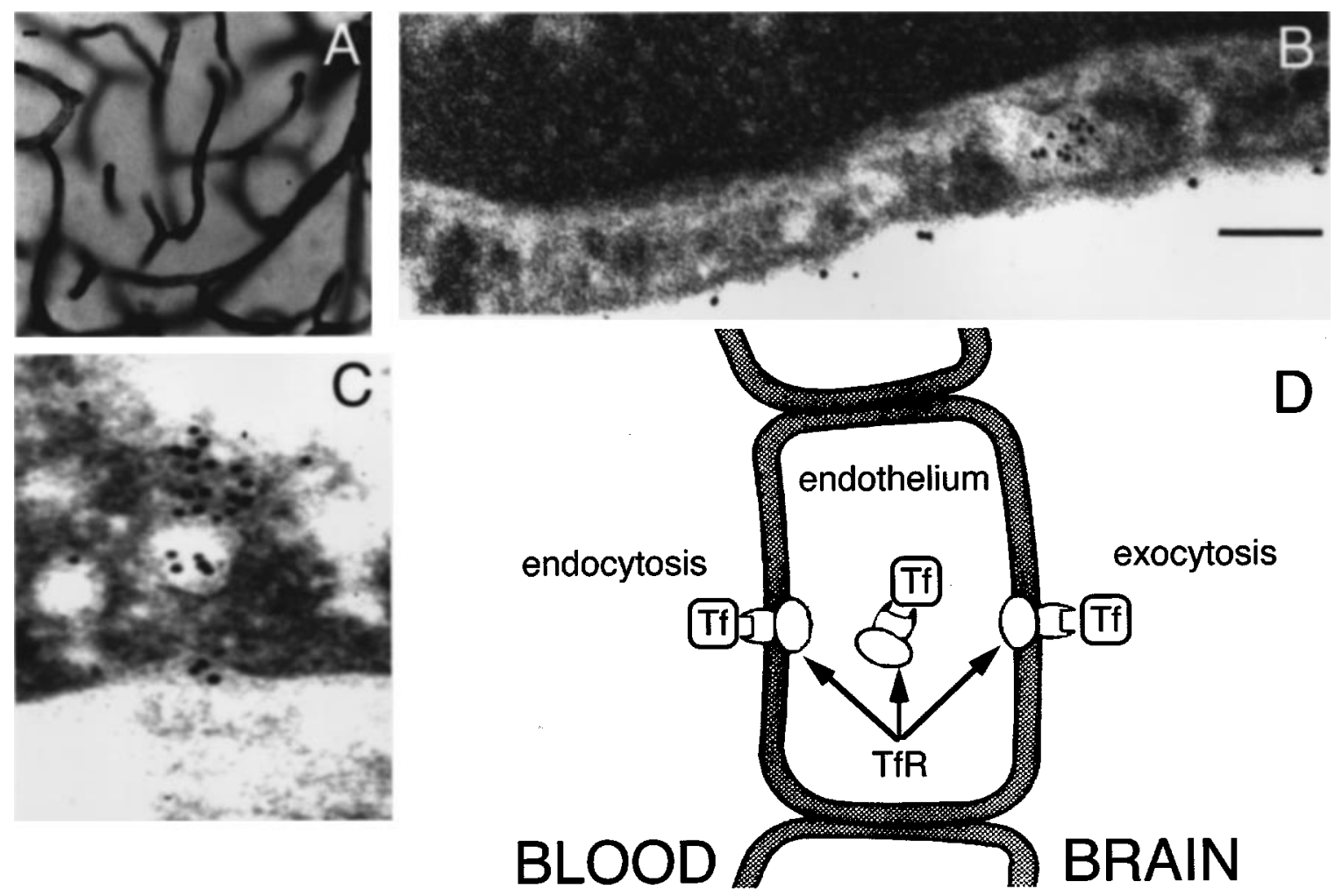

Figure 8 (A) Silver-enhanced vibratome section of rat brain perfused with OX26/gold conjugate in vivo. The coronal section is at the level of the frontal cortex. The magnification bar $=10 \mu \mathrm{m}$. (B) Electron micrograph of a brain capillary endothelial cell after perfusion of rat brain in vivo with the OX26/gold conjugate. The study shows dispersed OX26/gold attached to the luminal plasma membrane and clustered in endosome-like vesicles. Magnification bar=100 nm. (C) High magnification showing clustering of OX26/gold conjugate within endosomal structures as well as exocytosis of the conjugate into brain interstitial fluid, via transport across the abluminal membrane. (D) A scheme for receptor-mediated transcytosis (RMT) of transferrin (Tf) through the brain capillary endothelium via the transferrin receptor (TfR). From Bickel et al (1994).

and Pardridge, 1987). Moreover, the binding of [125I]insulin to human brain capillaries was also saturable and the molecular weight of the insulin binding site was identified by electrophoretic techniques and shown to be identical to the molecular weight of the insulin receptor (Pardridge et al, 1985). This provides evidence that the transport of insulin through the BBB in vivo is a receptor-mediated process.

A monoclonal antibody (MAb) to the human insulin receptor (HIR) was used to visualize the BBB insulin receptor in Old World primate brain immunocytochemically as shown in B of Figure 9 (Pardridge et al, 1995). The HIRMAb may be used as a BBB drug delivery vector by targeting the BBB insulin receptor (IR), as depicted in C of Figure 9. Drugs may be conjugated to brain drug delivery vectors such as the HIRMAb using avidin-biotin technology. In this approach, a conjugate of the HIRMAb and streptavidin is prepared in parallel with monobiotinylation of the drug that is normally not transported through the BBB (Pardridge, 1991). The 40 amino acid peptide, $\mathrm{A} \beta^{1-40}$, is a potential amyloid imaging agent should this molecule be made transportable through the BBB (Saito et al, 1995). Therefore, biotinylated $A \beta^{1-40}$ was radiolabeled and attached to a conjugate of HIRMAb and streptavidin and administered intravenously to anesthetized Rhesus monkeys (Wu et al, 1997). As shown by the QAR scan in D of Figure 9, there is robust uptake of the $\mathrm{A} \beta^{1-40}$ following conjugation to the HIRMAb BBB drug delivery system. In contrast, no visible brain uptake was observed when the peptide radiopharmaceutical was administered without attachment to the BBB drug delivery system. Vector-mediated brain drug delivery has been demonstrated in several other systems using this BBB delivery system. An epidermal growth factor (EGF) peptide radiopharmaceutical has been delivered across the BBB for purposes of imaging brain tumors (Kurihara et al, 1999). A vasoactive intestinal peptide (VIP) pharmaceutical has been delivered to brain for purposes of enhancing cerebral blood flow ( $\mathrm{Wu}$ and Pardridge, 1996). A brain derived neurotrophic factor (BDNF) pharmaceutical has been delivered across the BBB with this 

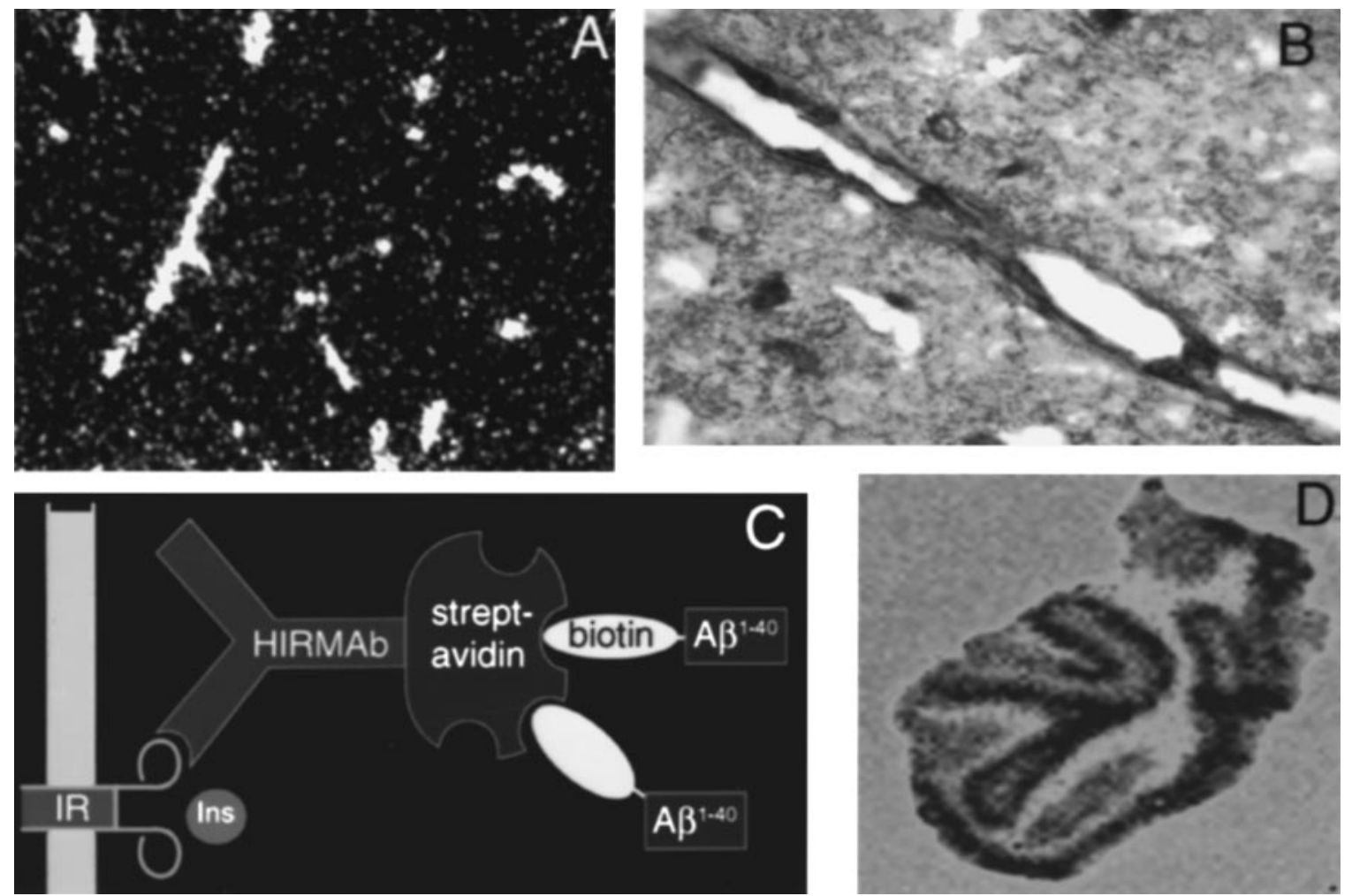

Figure 9 (A) Thaw-mount autoradiogram with a darkfield illumination of 1 month old rabbit brain obtained after a 10 min carotid artery perfusion of $\left[{ }^{125} \mathrm{I}\right]$-insulin. Silver grains trapped within the vessels are shown, and silver grains are also distributed throughout the brain parenchyma, indicative of transport of $\left[{ }^{125} \mathrm{I}\right]$-insulin through the BBB and into brain in vivo. From Duffy and Pardridge (1987). (B) Light microscopic immunocytochemistry of frozen sections of Rhesus monkey brain immunostained with the 83-14 monoclonal antibody to the human insulin receptor (HIR). A continuous immunostaining is indicative of endothelial origin of the BBB insulin receptor. From Pardridge et al (1995). (C) A scheme for drug delivery of a peptide radiopharmaceutical, A $\beta^{1-40}$, which is monobiotinylated and attached to a conjugate of the HIR monoclonal antibody (MAb) and streptavidin (SA). The complex undergoes a receptor-mediated transcytosis through the BBB via the insulin receptor (IR). The HIRMAb binds to an exofacial epitope on the IR that is removed from the binding site for insulin (Ins). (D) Phosphorimager scan of the occipital hemisphere of brain of a Rhesus monkey obtained $3 \mathrm{~h}$ after the intravenous injection of $\left[{ }^{125} \mathrm{I}\right]-\mathrm{A} \beta^{1-40}$ that was monobiotinylated and attached to the HIRMAb/SA BBB drug delivery system. There is robust brain uptake of the peptide radiopharmaceutical attached to the drug delivery system and the areas of gray matter are clearly delineated from the white matter tracks. From Wu et al (1997).

system for neuroprotection of hippocampal CA1 neurons following transient forebrain ischemia $(\mathrm{Wu}$ and Pardridge, 1999)

Subsequent to transport through the BBB, the conjugate may undergo receptor-mediated endocytosis into brain cells expressing the TfR or HIR, which are ubiquitously expressed throughout the brain (Mash et al, 1990). Following endocytosis into brain cells, the conjugate is transferred to the lysosomal compartment and is degraded. If a radionuclide is attached, this is subsequently exported from brain to blood with a $t_{1 / 2}$ in primates, in the case of [ $\left.{ }^{125} \mathrm{I}\right]$, of $16 \mathrm{~h}$ (Wu et al, 1997).

\section{Virus delivery through the blood-brain barrier}

Measles and encephalomyelitis, like MS or EAE, have an early peri-venular infiltration of mononuclear cells with peri-venular demyelination (Gendelman et al, 1984). Canine distemper virus
(CDV) infects brain via transport across the BBB in an analogous fashion with the measles virus (Axthelm and Krakowa, 1987). The measles virus infection of the CNS may be widespread as $30-50 \%$ of children infected with measles have CNS infection (Axthelm and Krakowa, 1987). In this event, capillaries contain virus before there is infiltration of brain by circulating white blood cells. Circulating viruses likely gain access to brain capillary endothelial cells via receptor mediated endocytosis of the virus from the plasma compartment. Virus coat proteins may act as ligands that trigger a receptor mediated endocytosis-like process at the luminal membrane of the capillary endothelium. For example, the basic amino acid transporter was originally identified as a murine retrovirus receptor (Kim et al, 1991). Once inside the capillary endothelial cell, the virus may enhance the progression of disease by causing BBB disruption which 
then facilitates the entry into brain of circulating plasma proteins, which are toxic to astrocytes (Nadal et al, 1995), and circulating immune cells (Soilu-Hanninen et al, 1994).

Cytokine-mediated blood-brain barrier disruption Intra-cerebral injection of interleukin-1 $\beta$ causes BBB disruption with loss of occludin and Z0-1 immunoreactivity at endothelial tight junctions. This is associated with increased adherence of polymorphornuclear leukocytes to the endothelial cell and increased phosphotyrosine immunoreactivty in endothelial cells (Bolton et al, 1998). The precise molecular mechanisms by which cytokines cause BBB disruption is not known. In cultured endothelial cells there is a release of nitric oxide (NO) following administration of cytokines such as interferon $\gamma$ or tumor necrosis factor (TNF)- $\alpha$ (Durieu-Trautman et al, 1993). The release of NO may lead to an increased perioxynitrite which then leads to nitration of protein tyrosine residues (Hooper et al, 1997). This provides the basis for new forms of MS treatment that use perioxynitrite scavengers such as uric acid, as well as inhibitors of nitric oxide synthase. NO synthase inhibitors block histamine-mediated BBB disruption of pial vessels in vivo (Mayhan, 1996). Chemokines may also play a role in $\mathrm{BBB}$ disruption. The intra-striatal injection of the CXC chemokine causes BBB disruption and the effect is greater in 21 day old mice as opposed to 90 day mice (Anthony et al, 1998). Whether chemokines play a role in virus induced BBB disruption is at present not known. One experimental model for this is the Semliki forest virus (SFV) which enhances the demyelination of EAE by infecting the brain capillary endothelium and causing BBB disruption (Soilu-Hanninen et al, 1994).

\section{Conclusions}

Overall CNS microvascular biology is regulated by paracrine interactions between the capillary en-

\section{References}

Anthony D, Dempster R, Fearn S, Clements J, Wells G, Perry VH, Walker K (1998). CXC chemokines generate age-related increases in neutrophil mediated brain inflammation and blood-brain barrier breakdown. Current Biology 8: 923-926.

Audus KL, Bartel RL, Hidalgo IJ, Borchardt RT-PCR (1990). The use of cultured epithelial and endothelial cells for drug transport and metabolism studies. Pharm Res 7: 435-451.

Axthelm MK, Krakowka S (1987). Canine distemper virus: the early blood-brain barrier lesion. Acta. Neuropatholog 75: 27-33. dothelial cell, the pericyte, and the astrocyte foot process. Functions frequently ascribed to the capillary endothelium are actually performed by either the capillary pericyte or the microvascular astrocyte foot process, which is separated from the capillary endothelium by a very short distance of only 20 nanometers. Pre-capillary arteriolar smooth muscle cells and capillary pericytes express DR-antigen, indicating antigen presentation in the brain occurs distal to the capillary endothelium. The brain capillary endothelial cell is highly enriched in specialized transport processes including carrier-mediated transport systems and receptor-mediated transcytosis processes. The latter may account for uptake of circulating viruses by brain endothelium. If certain viral coat proteins act as ligands for BBB RMT processes, then this will allow for BBB uptake of the circulating virus. With respect to $\mathrm{BBB}$ methodologies, there is a wide array of techniques available for studying this important membrane (Figure 1).

Physiologic techniques may now be correlated with biochemical and molecular biological methods using freshly isolated laboratory animal or human brain capillaries. Capillary cells may be grown in tissue culture to form an 'in vitro BBB' model. However, owing to the marked de-differentiation of brain capillary endothelial cells grown in culture, even in the presence of astrocyte co-cultures, it is difficult to extrapolate data obtained with the in vitro BBB model to the in vivo situation. Whenever possible, it is essential in BBB research to have in vitro/in vivo correlations whereby studies with the in vitro BBB model are performed in parallel with in vivo investigations.

\section{Acknowledgements}

Daniel Jeong skilfully prepared the manuscript. This work was supported by NIH grant NS-25554.

Bickel U, Kang YS, Yoshikawa T, Pardridge WM (1994), In vivo demonstration of subcellular localization of anti-transferrin receptor monoclonal antibody-colloidal gold conjugate within brain capillary endothelium. $J$ Histochem Cytochem 42: $1493-1497$.

Blumcke I, Eggli P, Celio MR (1995). Relationship between astrocyte foot processes and "perineuronal nets' in rat neocortex. GLIA 15: $131-140$

Boado RJ, Pardridge WM (1990). Molecular cloning of the bovine blood-brain barrier glucose transporter cDNA and demonstration of phylogenetic conservation of the 5'-untranslated region. Mol Cell Neurosci 1: 224-232. 
Boado RJ, Pardridge WM (1991). A one-step procedure for isolation of poly A+mRNA from isolated brain capillaries and endothelial cells in culture. J Neurochem 57: 2136-2139.

Boado RJ, Pardridge WM (1994). Differential expression of $\alpha$-actin mRNA and immunoreactive protein in brain microvascular pericytes and smooth muscle cells. $J$ Neurosci Res 39: 430-435.

Bolton SJ, Anthony DC, Perry VH (1998). Loss of the tight junction proteins occludin and zonula occludens-1 from cerebral vascular endothelium during neutrophilinduced blood-brain barrier breakdown in vivo. Neurosci 86: $1245-1257$.

Bowman PD, Ennis SR, Rarey KE, Betz AL, Goldstein GW (1983). Brain microvessel endothelial cells in tissue culture: a model for study of blood-brain barrier permeability. Annal Neurol 14: 296-402.

Broman T (1964). Blood-brain barrier damage in multiple sclerosis supravital test-observations. Acta Neurol Scand 40: $21-24$.

Cancilla PA, Baker RN, Pollack PS, Frommes SP (1972). The reaction of pericytes of the central nervous system to exogenous protein. Lab Invest 26: 376-383.

Cohen Z, Ehret M, Maitre M, Hamel E (1995). Ultrastructural analysis of tryptophan hydroxylase immunoreactive nerve terminals in the rat cerebral cortex and hippocampus: their associations with local blood vessels. Neurosci 66: 555-569.

Cordon-Cardo C, O’Brien JP, Casals D, Rittman-Grauer L, Biedler JL, Melamed MR, Bertino JR (1989). Multi-drug resistance gene (P-glycoprotein) is expressed by endothelial cells at blood-brain barrier sites. Proc Natl Acad Sci USA 86: 695-698.

Daniel PM, Lam DK, Pratt OE (1981). Changes in the effectiveness of the blood-brain and blood-spinal cord barriers in experimental allergic encephalomyelitis. $J$ Neurol Sci 52: 211-219.

DeBault LE, Kahn LE, Frommes SP, Cancilla PA (1979). Cerebral microvessels and derived cells in tissue culture: isolation and preliminary characterization. In Vitro 7: 473-487.

Dehouck MP, Meresse S, Delorme P, Fruchart JC, Cecchelli R (1990). An easier, reproducible, and mass-production method to study the blood-brain barrier in vitro. J Neurochem 54: 1798-1801.

Dore-Duffy P, Washington RA, Balabanov R (1994). Cytokine-mediated activation of cultured CNS microvessels: as system for examining antigenic modulation of CNS endothelial cells, and evidence for long-term expression of the adhesion protein E-selectin. J Cereb Blood Flow Metab 14: 837-844.

Duffy KR, Pardridge WM (1987). Blood-brain barrier transcytosis of insulin in developing rabbits. Brain Res 420: $32-38$.

Durieu-Trautmann O, Federici C, Creminon C, FoignantChaverot N, Roux F, Claire M, Strosberg AD, Couraud PO (1993). Nitric oxide and endothelin secretion by brain microvessel endothelial cells: regulation by cyclic nucleotides. J Cell Physiol 155: 104-111.

Gendelman HE, Wolinsky JS, Johnson RT, Pressman NJ, Pezeshkpour GH, Boisset GF (1984). Measles encephalomyelitis. Lack of evidence of viral invasion of the central nervous system and quantitative study of the nature of demyelination. Ann Neurol 15: 353-360.
Golden PL, Pardridge WM (1999). P-glycoprotein on astrocyte foot processes of unfixed isolated human brain capillaries. Brain Res 819: 143-146.

Herman IM, D’Amore PA (1985). Microvascular pericytes contain muscle and nonmuscle actins. J Cell Biol 101: $43-52$.

Hooper DC, Bagasra O, Marini JC, Zborek A, Ohnishi ST, Kean R, Champion JM, Sarker AB, Bobroski L, Farber JL, Akaike T, Maeda H, Koprowski H (1997). Prevention of experimental allergic encephalomyelitis by targeting nitric oxide and peroxynitrite: implications for the treatment of multiple sclerosis. Proc Natl Acad Sci USA 94: 2528-2533.

Hurwitz AA, Berman JW, Rashbaum WK, Lyman WD (1993). Human fetal astrocytes induce the expression of blood-brain barrier specific proteins by autologous endothelial cells. Brain Res 625: 238-243.

Jette L, Tetu B, Beliveau R (1993). High levels of Pglycoprotein detected in isolated brain capillaries. Biochim Biophys Acta 1150: 147-154.

Kacem K, LaCombe P, Seylaz J, Bonvento G (1998). Structural organization of the perivascular astrocyte endfeet and their relationship with the endothelial glucose transporter: a confocal microscopy study. GLIA 23: 1-10.

Kim JW, Closs EI, Albritton LM, Cunningham JM (1991). Transport of cationic amino acids by the mouse ecotropic retrovirus receptor. Nature 352: 725-728.

Kurihara A, Deguchi Y, Pardridge WM (1999). Epidermal growth factor radiopharmaceuticals: ${ }^{111}$ In chelation, conjugation to a blood-brain barrier delivery vector via a biotin-polyethylene linker, pharmacokinetics, and in vivo imaging of experimental brain tumors. Bioconj Chem 10: $502-511$

Lasbennes R, Gayet J (1983). Capacity for energy metabolism in microvessels isolated from rat brain. Neurochem Res 9: 1-9.

Liwnicz BH, Leach JL, Yeh HS, Privitera M (1990). Pericyte degeneration and thickening of basement membranes of cerebral microvessels in complex partial seizures: electron microscopic study of surgically removed tissue. Neurosurg 26: 409-420.

Mash DC, Pablo J, Flynn DD, Efange SM, Weiner WJ (1990). Characterization and distribution of transferrin receptors in the rat brain. I Neurochem 55: 19721979.

Mayan WG (1996). Role of nitric oxide in histamineinduced increases in permeability of the blood-brain barrier. Brain Res 743: 70-76.

McClellan G, Weisberg A, Lin LE, Rose D, Ramaciotti C, Winegrad S (1993). Endothelial cells are required for the cAMP regulation of cardiac contractile proteins. Proc Natl Acad Sci USA 90: 2885-2889.

Meyer J, Rauh J, Galla HJ (1991). The susceptibility of cerebral endothelial cells to astroglial induction of blood-brain barrier enzymes depends on their proliferative state. J Neurochem 57: 1971-1977.

Nadal A, Fuentes E, Pastor J, McNaughton PA (1995). Plasma albumin is a potent trigger of calcium signals and DNA synthesis in astrocytes. Proc Natl Acad Sci USA 92: $1426-1430$.

Nedergaard M (1994). Direct signaling from astrocytes to neurons in cultures of mammalian brain cells. Science 263: $1768-1772$. 
Nehls V, Drenckhahn D (1991). Heterogeneity of microvascular pericytes for smooth muscle type alpha-actin. J Cell Biol 113: $147-154$.

Pardridge WM (1991). In: Peptide Drug Delivery to the Brain. Pardridge WM (ed) Raven Press: New York, pp $1-357$.

Pardridge WM (1998a). Blood-brain barrier methodology and biology. In: Introduction to the Blood-brain Barrier: Methodology, Biology, and Pathology. Pardridge WM (ed). Cambridge University Press: Cambridge, UK, pp 1-8.

Pardridge WM (1998b). Isolated brain capillaries: an in vitro model of blood-brain barrier research. In: Introduction to the Blood-Brain Barrier: Methodology, Biology, and Pathology. Pardridge WM (ed). Cambridge University Press: Cambridge, UK, pp 49-61.

Pardridge WM (1999). A morphological approach to the analysis of blood-brain barrier transport function. In Brain Barrier Systems. Aflred Benzon Symposium 45 O. Paulson et al, (eds.). Munksgaard: Copenhagen. In press.

Pardridge WM, Eisenberg J, Yang J (1985). Human bloodbrain barrier insulin receptor. J Neurochem 44: 1541 1550.

Pardridge WM, Eisenberg J, Yang J, Tourtelotte WW (1987). Isolation of intact capillaries and capillary plasma membranes from frozen human brain. $J$ Neurosci Res 18: $352-257$.

Pardridge WM, Golden PL, Kang YS, Bickel U (1997). Brain microvascular and astrocyte localization of $\mathrm{p}$ glycoprotein. J Neurochem 68: 1278-1285.

Pardridge WM, Kang YS, Buciak JL, Yang J (1995). Human insulin receptor monoclonal antibody undergoes high affinity binding to human brain capillaries in vitro and rapid transcytosis through the blood-brain barrier in vivo in the primate. Pharm Res 12: 807816.

Pardridge WM, Triguero D, Yang J, Cancilla PA (1990). Comparison of in vitro and in vivo models of drug transcytosis through the blood-brain barrier. J Pharmacol Exp Ther 253: 884-891.

Pardridge WM, Yang J, Buciak J, Tourtellotte WW (1989). Human brain microvascular DR antigen. J Neurosci Res 23: $337-341$.

Paspalas CD, Papadopoulos GC (1996). Ultrastructural relationships between noradrenergic nerve fibers and non-neuronal elements in the rat cerebral cortex. GLIA 17: $133-146$.

Paulson OB, Newman EA (1987). Does the release of potassium from astrocyte endfeet regulate cerebral blood flow? Science 237: 896-898.

Pollack IF, Lund RD (1990). The blood-brain barrier protects foreign antigens in the brain from immune attack. Exper Neurol 108: 114-121.

Risau W, Dingler A, Albrecht U, Dehouck MP, Cecchelli $R$ (1992). Blood-brain barrier pericytes are the main source of $\gamma$-glutamyltranspeptidase activity in brain capillaries. I Neurochem 58: $667-672$.

Saito Y, Buciak J, Pardridge WM (1995). Vector-mediated delivery of $\left[{ }^{125} \mathrm{I}\right]$-labeled $\beta$-amyloid peptide $\mathrm{A} \beta^{1-40}$ through the blood-brain barrier and binding to Alzheimer's disease amyloid of the $\mathrm{A} \beta^{1-40}$ vector complex. Proc Natl Acad Sci USA 90: 10227-10231.
Smith QR, Rapoport SI (1986). Cerebrovascular permeability coefficients to sodium, potassium and chloride. J Neurochem 46: 1732-1742.

Soilu-Hanninen M, Eralinna J-H, Hukkanen V, Roytta M, Salmi AA, Salonen R (1994). Semliki forest virus infects mouse brain endothelial cells and causes blood-brain barrier damage. J Virol 68: 6291-6298.

Stanness KA, Westrum LE, Fornaciari E, Mascagni P, Nelson JA, Stenglein SG, Myers T, Janigro D (1997). Morphological and functional characterization of an in vitro blood-brain barrier model. Brain Res 771: 329342 .

Stewart PA (1994). Glial-vascular relations, In: KMA Welch, LR Caplan, DL Reis (eds). Primer on Cerebrovascular Diseases. Academic Press: New York, pp $17-20$.

Thompson SE, Audus KL (1994). Leucine-enkephalin metabolism in brain microvessel endothelial cells. Peptides 15: 109-116.

Tilling T, Korte D, Hoheisel D, Galla HJ (1998). Basement membrane proteins influence brain capillary endothelial barrier function in vitro. J Neurochem 71: 11511157.

Tsukada N, Behan WM, Behan PO (1985). Search for autoantibodies to endothelial and smooth muscle cells in patients with multiple sclerosis. Acta Neuropath 66: $134-139$

Tsukada N, Koh CS, Yanagisawa N, Okano A, Behan WM, Behan PO (1987). A new model for multiple sclerosis: chronic experimental allergic encephalomyelitis induced by immunization with cerebral endothelial cell membrane. Acta Neuropath 73: 259-266.

VanBree JB, de Boer AG, Verhoef JC, Danhof M, Breimer DD (1988). Transport of vasopressin fragments across the blood-brain barrier: In vitro studies using monolayer cultures of bovine brain endothelial cells. J Pharm Exp Ther 249: 901-905.

Vass K, Lassmann H, Wekerle H, Wisniewski HM (1986). The distribution of Ia antigen in the lesions of rat acute experimental allergic encephalomyelitis. Acta Neuropathol 70: 149-160.

Washington R, Burton J, Todd RF, Newman W, Dragovic L, Dore-Duffy P (1994). Expression of immunologically relevant endothelial cell activation antigens on isolated central nervous system microvessels from patients with multiple sclerosis. Ann Neurol 35: 8997.

Wong GH, Bartlett PF, Clark-Lewis I, Battye F, Schrader JW (1984). Inducible expression of $\mathrm{H}-2$ and Ia antigens on brain cells. Nature 310: 688-691.

Wu D, Pardridge WM (1996). CNS pharmacologic effect in conscious rats after intravenous injection of a biotinylated vasoactive intestinal peptide analogue coupled to a blood-brain barrier drug delivery system. J Pharmacol Exp Ther 279: 77-83.

Wu D, Pardridge WM (1999). Neuroprotection with noninvasive neurotrophin delivery to brain. Proc Natl Acad Sci USA 96: 254-259.

Wu D, Yang J, Pardridge WM (1997). Drug targeting of a peptide radiopharmaceutical through the primate blood-brain barrier in vivo with a monoclonal antibody to the human insulin receptor. J Clin Invest 100: $2842-2848$ 